\title{
Application of Low-Voltage FESEM and TEM to the Study of Mineral and Organic-Matter Components in Unconventional Gas Shales, With a Focus on Organic Pores Structure
}

\author{
Patrick Smith ${ }^{1}$ and Tongwei Zhang ${ }^{1}$ \\ 1. Bureau of Economic Geology, Jackson School of Geosciences, The University of Texas at Austin, \\ USA
}

Shale, a fine-grained clastic sedimentary rock, is defined in terms of particle size, not composition. Shale particles, which range in size from less than one hundred microns to nanometers, are composed of mineral grains, clays, and organic matter deposited simultaneously, usually in water environments. Shale gases are unconventional gas systems in which the shale is both the source of and the reservoir for methane, which is derived from the organic matter within the shale through biogenic and/or thermogenic processes. Natural gas stored in shale is thought to exist in one of three forms: (1) free gas in pores and fractures, (2) absorbed gas in organic matter and on inorganic minerals, and (3) dissolved gas in oil and water. ${ }^{1}$ It has been reported that organic-matter porosity $(\leq 15 \mathrm{~nm}$ pore size and \% porosity) is a major factor in estimating reserves and production from gas-shale reservoirs. ${ }^{2,3,4}$ One of the major issues confronting researchers when studying porosity in gas shales is reaching the spatial resolution $(<15 \mathrm{~nm})$ for accurate pore imaging.

Conventional field-emission scanning electron microscopy (CFESEM) of coated Argon ion-milled samples is routinely used by investigators to characterize the evolution of the mineralogical and organic carbon structure in oil/gas shales. This methodology is limited to qualitative interpretation of pores $<15 \mathrm{~nm}$. It is critical for any porosity analysis of oil/gas shales to be able to clearly image all pore sizes in a viewed area.

In this talk samples previously examined by CFESEM were reinvestigated using two high-resolution microscopic methods: $(1)<1 \mathrm{Kev}$ low-voltage mode FESEM, which has many advantages when studying low-Z organic material in shales. (2) $300 \mathrm{Kev}$ high-resolution transmission electron microscopy (HRTEM), which can provide a unique high-resolution three- dimensional view of the relationship of the organic matter with the mineralogical rock fabric and graphene/amorphous atomic structures.

Samples were selected based on their unique nitrogen-gas adsorption-size distribution pattern. Nitrogengas adsorption is a common bulk-volumetric method application used to derive pore size and \% porosity (figure 1). ${ }^{5}$ Ten $10 \times 10 \mathrm{~mm}$ cube samples were prepared using a standard cross-sectional Argon -ion milling technique. ${ }^{6}$ Five samples were coated with $\leq 5 \mathrm{~nm}$ of Iridium and then characterized using an FEI Nova Nano SEM 430 (FESEM) fitted with an energy-dispersive spectrometer (EDS) at the Bureau of Economic Geology (BEG). The remaining five uncoated, prepared samples were then shipped for analysis to the Zeiss and FEI demonstration laboratories. Analyses were performed in their SEM's in low-voltage mode. Three HRTEM samples from the uncoated group were prepared and imaged at the Cerium Laboratories in Austin, Texas. Site-specific areas were prepared using the focused ion beam (FIB) sliceextraction technique. ${ }^{7}$ The extracted slices (lamella) were then transferred for HRTEM observation. Figure 2 illustrates signal capture from the three different microscopic techniques. 


\section{References:}

[1] RJ Hill, YC Tang and IR Kaplan, Organic Geochemistry 34 (2003), p. 1651.

[2] RG Loucks et al, AAPG Bulletin 96 (2012), p. 1071.

[3] KL Milliken, M Rudnicki and DN Awwiller, AAPG Bulletin 97 (2013), p. 177.

[4] FP Wang et al, SPE-124253, SPE Annual Technical Conference (October 4-7, 2009).

[5] T Zhang, GS Ellis and SC Ruppel, Organic Geochemistry 47 (2012), p. 120.

[6] RG Loucks et al, Journal of Sedimentary Research 79 (2009), p. 848.

[7] MR Lee, PA Bland and G Graham, Mineralogical Magazine 67 (2003), p. 581.

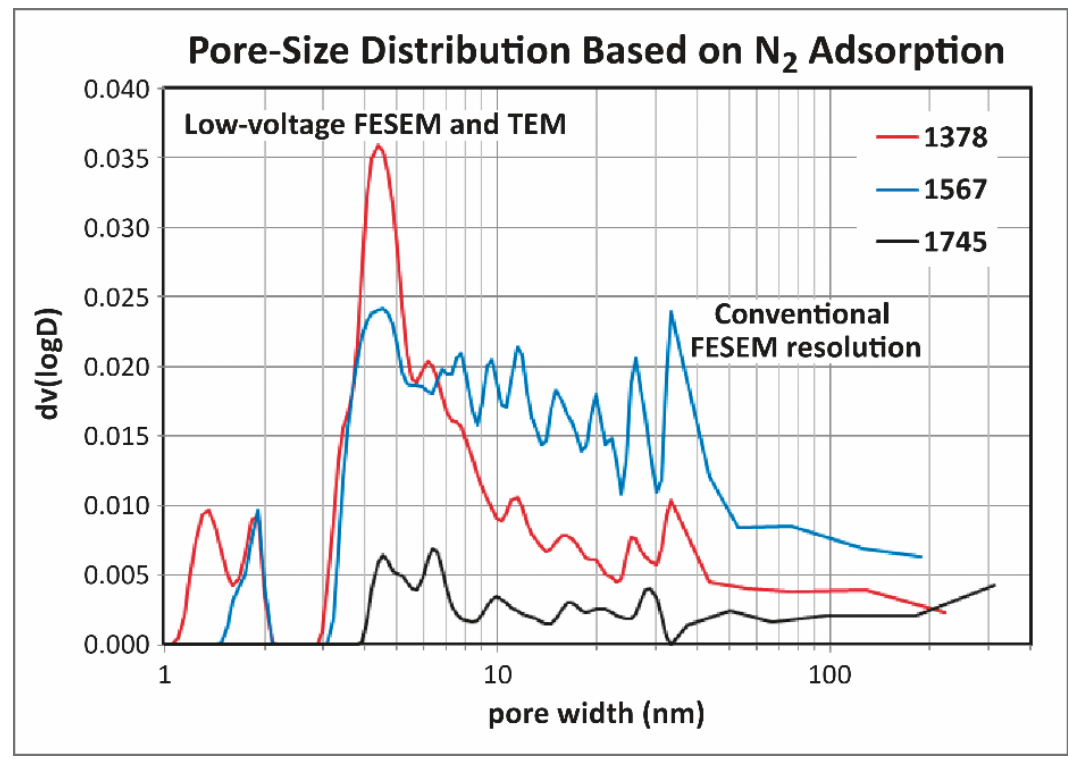

Figure 1. Volumetric pore-body-analysis technique. This graph has no context and says nothing about shape, distribution, or associations of pores.

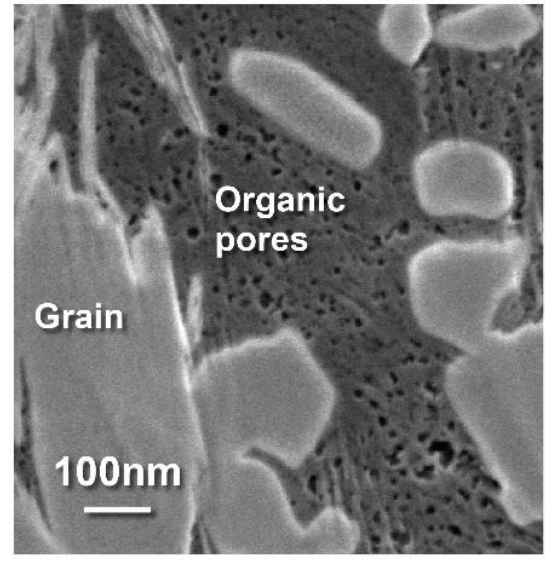

A. $600 \mathrm{ev}$ secondary electron signal (uncoated); $2 \mathrm{~nm}$ resolution.

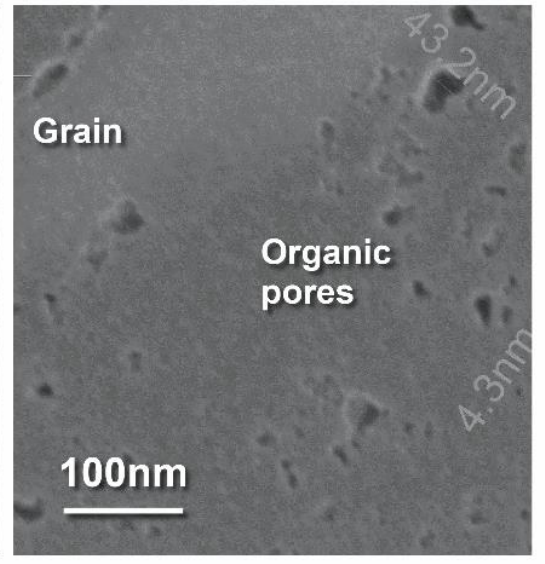

B. $10 \mathrm{Kev}$ secondary electron signal ( $~ 5 \mathrm{~nm}$ iridium coating); $\sim 5 \mathrm{~nm}$ resolution.

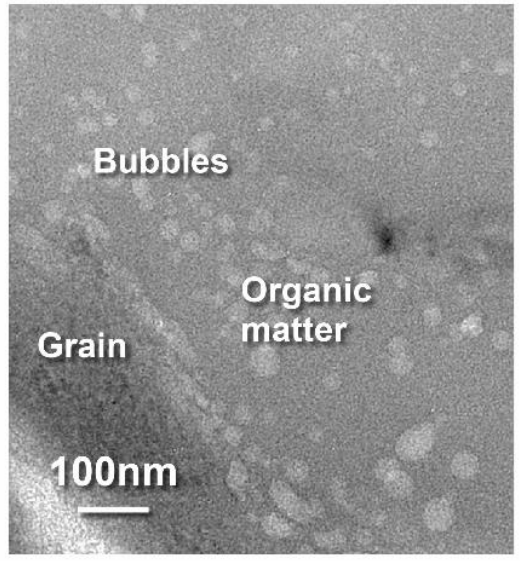

C. $300 \mathrm{Kev}$ TEM bright-field image; $0.1 \mathrm{~nm}$ resolution.

Figure 2. A, B, and $\mathbf{C}$ illustrate signal capture from different microscopic techniques. 